\title{
O BRASIL E A SEGUNDA REVOLUÇÃO ACADÊMICA
}

\author{
Daniella Rocha de Almeida (PG/UEMS) \\ Angela Duran Aparecida da Cruz (UEMS)
}

\begin{abstract}
Resumo
A primeira revolução na academia ocorre no final do século XVII nos Estados Unidos, agregando a pesquisa como missão da Universidade, além das atividades de ensino. Logo, apresenta-se suas consequências e desafios, envolvendo tensões entre as atividades de pesquisa e de ensino. Embora esta primeira revolução ainda esteja em processo de desenvolvimento, uma segunda revolução teve início na segunda metade do século XX. A partir de experiências em Universidades como MIT, Stanford e Harvard, surge o conceito de Universidade Empreendedora, que agrega uma nova missão, voltada ao desenvolvimento econômico e social. Esta nova visão aproxima a Universidade das demandas da sociedade onde está inserida e posiciona a academia como um importante vetor do desenvolvimento econômico e social. Deste então, a academia tem convivido com as tensões geradas pelo novo ambiente, envolvendo a sua missão de ensino (original), pesquisa (primeira revolução) e desenvolvimento econômico e social (segunda revolução). Como a universidade brasileira se posiciona diante desse cenário? Podemos dizer que as pesquisas acadêmicas no Brasil têm servido à população? A sociedade espera mais da academia? Como o setor privado pode se relacionar com a universidade e vice-versa? Qual a importância dos professores para o desenvolvimento econômico e social no país por meio da pesquisa? Algumas discussões surgem de forma instigante quando se relaciona a educação superior com o desenvolvimento econômico e social do país. Na ânsia de descobrir como o Brasil está se movimentando nesse cenário e diante de questões como as que foram citadas anteriormente, o presente artigo se desenvolve.
\end{abstract}

Palavras-chave: Universidades. Brasil. Revolução. Pesquisa. Desenvolvimento.

As universidades passaram por grandes transformações desde o seu surgimento, no século XI na Europa, até os dias atuais. No início, a universidade tinha como principal missão a transmissão do conhecimento dos professores para os alunos, por isso suas atividades eram totalmente voltadas para o ensino. Etzkowitz (1998 apud AUDY, 2006) identifica duas grandes revoluções pelas quais as universidades já passaram durante a sua história. Quando o mundo se deparou com a revolução industrial as universidades também se depararam com um grande aumento de sua demanda e precisavam atender às necessidades da sociedade. Foi neste período que, segundo Etzkowitz, a primeira revolução acadêmica ocorreu, no final do século XVII e meados do século XVIII, com força total na Europa e nos Estados Unidos. Tem-se notícia de que a primeira universidade que se adequou ao novo modelo foi a Universidade de Berlim. A partir desta revolução, padrões

\begin{tabular}{|l|l|l|l|l|l|}
\hline Interface da Educ. & Paranaíba & v. 1 & n. 1 & p. 53-65 & 2010 \\
\hline
\end{tabular}


institucionais foram criados agregando a pesquisa como missão da Universidade, indo além das atividades de ensino. Importante afirmar que esta primeira revolução ainda apresenta suas consequências e desafios, pois nos dias atuais existem tensões entre as atividades de pesquisa e de ensino em várias universidades, portanto, é certo considerar que esta primeira revolução ainda esteja em processo de desenvolvimento.

Depois da segunda guerra mundial, a segunda revolução acadêmica teve início. A partir de experiências em Universidades como MIT, Stanford e Harvard, surgiu o conceito de Universidade Empreendedora, que agrega uma nova missão, voltada ao desenvolvimento econômico e social por meio da transferência de conhecimento para a sociedade, ultrapassando as funções do ensino e da pesquisa. Nesta nova visão, a universidade se aproxima das demandas da sociedade onde está inserida e incorpora a responsabilidade de importante pilar do desenvolvimento econômico e social. A partir dessa postura, o conhecimento está diretamente ligado à economia e ao desenvolvimento. A universidade, desde a segunda revolução, tem convivido com as tensões geradas pelo novo ambiente, envolvendo a sua missão de ensino (original), pesquisa (primeira revolução) e desenvolvimento econômico e social (segunda revolução).

A segunda revolução na academia (ETZKOWITZ, 1998 apud AUDY, 2006), gerou o conceito de Universidade Empreendedora, sendo que alguns autores associam o conceito à inovação e preferem utilizar o termo "Universidade Inovadora" (CLARK, 2003 apud AUDY, 2006).

A inovação é um conceito profundamente associado à ciência e à pesquisa científica e tecnológica. Segundo Sáenz e Capote (2002 apud AUDY, 2006), a definição de ciência reflete a complexidade e os diferentes aspectos envolvidos nesta definição. $\mathrm{O}$ autor entende que a ciência pode ser considerada, simultaneamente, como uma instituição, um método. Pode ser compreendida como uma tradição cumulativa de conhecimentos, um vetor principal na manutenção e desenvolvimento da produção, e "uma das influências mais poderosas entre as que dão forma às crenças e atitudes relativas ao universo e ao homem" (SÁENZ e CAPOTE, 2002 apud AUDY, 2006, p.68).

Os avanços científicos sempre influenciaram as mudanças significativas nas forças produtivas. Já a pesquisa, é a forma como a ciência se faz ou se desenvolve. O Manual Frascati (1993 apud AUDY, 2006) define pesquisa e desenvolvimento como o trabalho

\begin{tabular}{|l|l|l|l|l|l|}
\hline Interface da Educ. & Paranaíba & v. 1 & n. 1 & p. 53-65 & 2010 \\
\hline
\end{tabular}


original realizado sistematicamente com o objetivo de aumentar o conhecimento e a utilização desta gama de conhecimentos para desenvolver novas aplicações. Neste sentido, a pesquisa pode ser básica (pesquisa original, teórica ou experimental, realizada principalmente com o objetivo de adquirir conhecimento ou uma maior compreensão dos fenômenos ou observações em estudo, sem o propósito de uma aplicação em particular) ou aplicada (pesquisa também original, realizada para adquirir novos conhecimentos dirigidos por objetivos específicos e práticos).

Ainda segundo o Manual Frascati (1993 apud AUDY, 2006), tecnologia pode ser compreendida como o conjunto dos conhecimentos científicos e empíricos, habilidades, experiências e organização requeridas para produção, distribuição, comercialização e utilização de bens e serviços. A tecnologia, enquanto atividade beneficia a vida do homem, buscando aplicações práticas para os conhecimentos já existentes.

Nas últimas décadas, mudanças radicais fizeram com que as universidades se abrissem para as demandas da sociedade, aumentando suas interações com empresas privadas, governo e instituições, criando ambientes de inovação e empresas nascentes. Nos últimos anos, Burton Clark (2003 apud AUDY, 2006 p. 65) tem usado o termo inovação com frequência na área acadêmica, onde sustenta que "a visão de uma Universidade Inovadora é o resultado das demandas da sociedade e da procura de sustentabilidade das instituições".

Neste sentido, a inovação está relacionada à resolução de problemas do dia-a-dia, de forma mais ágil e empreendedora, e ao desenvolvimento de novas oportunidades de crescimento profissional e social (geração de novas empresas, geração de emprego e renda, desenvolvimento e aplicação de novas tecnologias, a busca constante de maior produtividade e competitividade, melhor qualidade de vida, mais cultura e conhecimento). Dentro desse novo cenário, a universidade desperta para novos horizontes, ultrapassando o espaço acadêmico e desenvolvendo sua própria sustentabilidade, gerando novas relações de emprego, assunto tão evidente nos países em desenvolvimento. Audy (2006) atenta para um fator interessante com relação ao mercado de trabalho dos egressos de nível superior. Acredita que o ambiente onde estão as melhores oportunidades para esses profissionais está cada vez mais relacionado às atividades autônomas, onde o requisito fundamental é a competência, acompanhada de habilidades e atitudes inovadoras. Partindo da ótica de

\begin{tabular}{|l|l|l|l|l|l|}
\hline Interface da Educ. & Paranaíba & v. 1 & n. 1 & p. 53-65 & 2010 \\
\hline
\end{tabular}


Audy, podemos verificar que os requisitos profissionais hoje exigidos estão diretamente ligados com a proposta de Universidade Inovadora.

Ao incorporar na academia o termo inovação, estamos destacando três aspectos fundamentais: interação com a sociedade (para a identificação das demandas), empresas (pois é neste tipo de organização que a inovação ocorre) e governo (como facilitados do processo). Em outras palavras, inovação significa P\&D (Pesquisa e Desenvolvimento), mais transferência de tecnologia. Neste sentido, qualidade deixa de ser um pressuposto único para a avaliação da universidade e inclui-se relevância como um item de avaliação igualmente importante. Ou seja, neste novo ambiente, qualidade passa a ser condição primária, porém não mais suficiente para a avaliação da universidade (AUDY, 2006).

Conforme Etzkowitz (1991 apud FUJINO e STAL, 2005), as universidades, além de suas clássicas atividades de ensino e pesquisa, estão, cada vez mais, incorporando uma terceira atividade: a atuação em desenvolvimento econômico local e regional. $\mathrm{O}$ autor ainda afirma que, dentro da Segunda Revolução, ocorre um novo acordo entre universidade e sociedade, no qual o financiamento público para a universidade está condicionado à sua contribuição direta para a economia. Esse novo formato sugere indagações sobre o futuro da universidade, porém defende-se que uma maior participação da universidade no desenvolvimento local poderá auxiliar em seu fortalecimento. Como sustenta Etzkowitz (1994, p.151 apud FUJINO e STAL, 2005), a nova postura da universidade pode "[...] transformar-se num processo de renascimento".

Hoje as universidades sofrem o processo da Segunda Revolução Acadêmica, pois vivem a emergência de se relacionarem com as empresas e vice-versa, numa interação com a finalidade de aplicar as pesquisas produzidas na academia e pulverizar os resultados para a sociedade.

Hoje em dia, a universidade atua em um contexto de complexidade e incerteza, no qual são exigidas novas formas de interação com a sociedade, visando a capturar suas necessidades e demandas. Neste balanço entre demanda e capacidade de resposta, a flexibilidade e a capacidade de adaptação são importantes, numa ação de muita cautela para que a universidade não perca seus valores acadêmicos, demonstrados nas atividades de ensino e pesquisa que ela desenvolve. Este balanço entre a tradição (representada pelos

\begin{tabular}{|l|l|l|l|l|l|}
\hline Interface da Educ. & Paranaíba & v. 1 & n. 1 & p. 53-65 & 2010 \\
\hline
\end{tabular}


valores acadêmicos) e a renovação (representada pelas novas demandas da sociedade) é o diferencial que as melhores universidades do futuro estão construindo hoje.

A história das duas revoluções, abordadas até aqui, trata-se de um cenário mundial, o que dará base para compreendermos o contexto de pesquisa e demanda em que a universidade brasileira se organiza atualmente. Antes de abordar diretamente o cenário da universidade brasileira contemporânea, gostaria de compartilhar algumas reflexões de Alvim Toffler, organizadas pelo INEP no livro Universidade no Brasil: concepções e modelos, com citação e comentários de Dilvo Ristoff (2006) (Diretor de estatística e avaliação da educação superior/INEP).

A educação brota a partir dessa imagem. Mesmo que não existam escolas na tribo, haverá um currículo - um conjunto de habilidades, valores e rituais que devem ser aprendidos. Aos meninos será ensinado como remover as cascas das árvores e como fazer canoas de troncos, da mesma forma como fizeram os seus antepassados. O professor nesse contexto, sabe o que está fazendo, convicto de que a tradição, o passado, funcionará no futuro.

O que acontecerá a essa tribo, no entanto, se continuar com os seus métodos tradicionais, sem saber que, 700 quilômetros acima, está sendo construída uma represa que secará o braço do rio à beira do qual vive? Repentinamente, a imagem de futuro - o conjunto de pressupostos nos quais os membros da tribo baseiam o seu comportamento presente - torna-se perigosamente enganosa. $\mathrm{O}$ amanhã não mais replicará o hoje. $\mathrm{O}$ investimento da tribo na preparação de seus filhos para viverem numa comunidade ribeirinha torna-se sem sentido e um desperdício potencialmente trágico. Uma imagem falsa de futuro destrói a relevância do esforço educacional.

Esta é a nossa situação hoje, com uma diferença: ironicamente somos nós, e não um bando de desconhecidos a milhares de quilômetros de distância, que estamos construindo a represa que aniquilará a cultura do presente. Nunca antes, qualquer cultura esteve sujeita a tão intenso bombardeio de mudanças tecnológicas, sociais e "info-psicológicas". Esta mudança acelera, e testemunhamos em todas as sociedades de alta tecnologia, que as velhas estruturas da era industrial já não conseguem mais desempenhar suas funções a contento.

E, no entanto, nossos líderes políticos em sua maior parte propagam o mito de que a sociedade industrial está destinada a se perpetuar indefinidamente. Como anciãos da tribo

\begin{tabular}{|l|l|l|l|l|l|}
\hline Interface da Educ. & Paranaíba & v. 1 & n. 1 & p. 53-65 & 2010 \\
\hline
\end{tabular}


ribeirinha, eles imaginam cegamente que as principais características do atual sistema social se estenderão indefinidamente no futuro. E a maiorias dos educadores, incluindo aqueles que se consideram agentes de mudanças, sem perceber, aceitam esse mito. E, assim, quando a mudança chegar, sua imagem de futuro provará estar não apenas obsoleta, mas "anti-adaptativa", pois não terá deixado lugar para a possibilidade de mudança radical" (TOFFLER, 1970).

O desenvolvimento de uma universidade não pode ser avaliado apenas pela demanda que ela responde no momento, mas principalmente pela visão de futuro que ela tem. Preparar-se para o futuro é uma questão de sobrevivência e evolução do ensino superior.

No Brasil, existem cursos profissionais, escolas de pós-graduação e programas de pesquisa de alta qualidade, a exemplo temos a USP, com grande produção acadêmica e considerada referência nacional. Mas o atraso com que as nossas instituições surgiram prejudica o desenvolvimento do país. Para se ter uma ideia, nos outros países da América latina, o surgimento das universidades datam do século XVI ou, no máximo, do século XIX, ao passo que as universidades brasileiras só surgiram nos anos 1930 e 1940. Com isso, o ensino superior brasileiro não teve participação em momentos importantes como a reforma universitária, que começou em Córdoba, Argentina, em 1918, e espalhou-se por muitos países da América Latina, como Argentina, Peru, Uruguai, Venezuela, México. A universidade brasileira gerou, então, uma forma diferente de autonomia e politização acadêmica, como também padrões acadêmicos que deixaram bastante a desejar.

Stal (1997 apud FUJINO e STAL, 2005) avalia que o processo de industrialização brasileiro é recente se comparado com o dos países desenvolvidos, tendo se iniciado na década de 1940, como forma de garantir a infraestrutura necessária para as indústrias automotivas, de equipamentos, química, elétrica e eletrônica, que se instalaram aqui, a partir da década de 1950. Como não havia recursos humanos para a criação de know how nacional, a aquisição se deu principalmente por acordos de assistência técnica, licenças e contratação de profissionais e estrangeiros. Foi no final da década de 1960 que o governo passou a se preocupar de forma mais presente com o desenvolvimento científico e tecnológico, criando planos e políticas específicos para a área, agências de fomento (FINEP), bancos e desenvolvimento (BNDES, por meio do seu programa de

\begin{tabular}{|l|l|l|l|l|l|}
\hline Interface da Educ. & Paranaíba & v. 1 & n. 1 & p. 53-65 & 2010 \\
\hline
\end{tabular}


desenvolvimento tecnológico, FUNTEC) e cursos de pós-graduação, com a criação da COPPE, em 1964, como cita Stal (1997 apud FUJINO, 2005).

Nesse período se deu a opção pelo modelo linear de inovação ou science push, dentre os vários modelos já existentes. Nesse modelo, o grande investimento em ciência gerou uma bagagem de conhecimento científico no país, que é então desfrutada pelas empresas no desenvolvimento de novos produtos e processos, gerando riqueza e, posteriormente, desenvolvimento econômico e social.

Assim, o governo brasileiro, considerou a relevância do desenvolvimento científico no país e concentrou investimentos em ciência, renovando a força das universidades e promovendo o treinamento de cientistas e pesquisados, concedendo um grande número de bolsas de mestrado e doutorado a cientista brasileiros para o aperfeiçoamento de seus estudos em escolas de primeira linha no exterior.

Segundo Buainain (2005 apud FUJINO e STAL, 2005), o resultado de tal modelo é que o Brasil, embora tenha conseguido obter índices razoáveis com a produção de artigos científicos publicados em periódicos internacionais (tendo aumentado sua participação na produção mundial de 0,4\% em 1981 para 1,4\% em 2001), acabou gerando indicadores de tecnologia (patentes) condenáveis. O número de patentes concedido pelo Escritório Americano de Patentes, medida utilizada para comparar os esforços de inovação nos diferentes países, indicou que o Brasil passou, no mesmo período, de 23 para 110, enquanto que a Coréia do Sul, no mesmo intervalo, saltou de 17 para 3.538 patentes, o que revela o baixo índice brasileiro de transformação de resultados de pesquisa acadêmica em desenvolvimento concreto.

Fujino e Stal (2005) consideram que no Brasil configura-se um processo embrionário no que diz respeito à segunda revolução acadêmica, onde a universidade ganha uma missão de inovadora. É sabido que a inovação se realiza nas empresas, com a oferta ao mercado de novos produtos e serviços. As universidades têm assumido, nos últimos anos, as mais variadas funções. Sua missão, além da educação e formação humana, inclui também a pesquisa e a extensão, e compete a elas assegurar o avanço da ciência. No caso das universidades brasileiras, apesar do aumento crescente da consciência sobre a necessidade de transferir à sociedade os resultados da pesquisa financiada com recursos públicos, não há uma política clara relativa à gestão da propriedade intelectual, o que

\begin{tabular}{|l|l|l|l|l|l|}
\hline Interface da Educ. & Paranaíba & v. 1 & n. 1 & p. 53-65 & 2010 \\
\hline
\end{tabular}


compromete a transferência desses resultados e sua transformação em inovação por parte das empresas.

Ainda segundo Fujino e Stal (2005), muitas políticas dos países desenvolvidos se espelharam nos resultados americanos após a implementação da Lei Bayh-Dole, de 1980, que permitiu às universidades patentear e licenciar, com exclusividade, invenções financiadas por fundos federais. Pesquisa realizada pela AUTM (Association of University Technology Managers, 2004) mostra que no período de 1991 a 2001 o número de invenções cresceu $84 \%$, a solicitação de novas patentes $238 \%$, os acordos de licenciamento $161 \%$ e os royalties, mais de $520 \%$.

Nos EUA, a Lei Bayh-Dole regulamentou o direito de propriedade intelectual das pesquisas feitas com recursos públicos nas universidades; no Brasil, uma iniciativa semelhante já se desenvolve. No final de 2004, foi implantada a Lei da Inovação brasileira (atual lei de propriedade intelectual), regulamentada pelo Decreto $\mathrm{N}^{\circ} 5.562$, estabelecendo um marco legal ao regulamentar e incentivar o processo de transferência dos resultados de pesquisas acadêmicas para as organizações.

O principal objetivo da Lei da Inovação é o desenvolvimento sustentável, estimulando as empresas a inovarem com o apoio científico da universidade e estimulando os pesquisadores inventores a proporcionarem o desenvolvimento concreto de suas pesquisas para a sociedade com o apoio das empresas privadas. Desta forma, a parceria entre empresa e universidade tem amparo legal para os dois lados, e dessa nova relação pode surgir uma crescente rede de empregos para o país.

Analisando a questão, com a regulamentação da nova lei no Brasil, será que os resultados serão tão expressivos como vemos nos EUA, na Alemanha ou no Reino Unido? Inicialmente, há um movimento de forma tímida por parte das universidades, governo e empresa, mas pelo menos a lei já resolve algumas dúvidas até então existentes a respeito da transferência de resultados acadêmicos para a sociedade.

Devemos considerar que o nosso contexto político-cultural é diferente do estadunidense. A lei de Inovação precisa contar com o interesse dos pesquisadores acadêmicos e com o comprometimento das universidades com a inovação. Conforme Fujino e Stal (2005), o ambiente universitário brasileiro ainda se mostra bastante isolado, desinteressado e, em alguns casos, descompromissado com os problemas da indústria, o

\begin{tabular}{|l|l|l|l|l|l|}
\hline Interface da Educ. & Paranaíba & v. 1 & n. 1 & p. 53-65 & 2010 \\
\hline
\end{tabular}


que colabora para uma situação distinta do contexto americano, quando da promulgação do Bayh-Dole Act. Em outras palavras, a "Segunda Revolução Acadêmica", conforme descrita por Etzkowitz (1993 apud FUJINO e STAL, 2005), ainda não se consolidou no Brasil.

Além de todos os obstáculos para investimento em P\&D que conhecemos num país em desenvolvimento como o Brasil, percebe-se que a universidade também não tem tido muito empenho para o crescimento de pesquisas dentro da academia, legitimando a cobrança da sociedade por uma maior participação das universidades na dinâmica do desenvolvimento econômico e social do país.

Segundo resultados da ONU, o Brasil apresenta um baixo nível de atividade patentária comparados aos dados internacionais. O número de patentes brasileiras em 2007 foi decepcionante, com apenas 384 patentes registradas enquanto os EUA lideraram a lista com nada menos que 52.280 patentes registradas.

Independentemente dos motivos, o fato é que a comunidade acadêmica não tem oferecido muito em termos de pesquisa à sociedade. As pesquisas científicas precisam ser mais valorizadas, começando pelo estímulo do próprio aluno a pesquisar, pois ele é um pesquisador em potencial.

Atualmente, existem alguns programas governamentais de incentivo à cooperação entre empresas e universidades para o desenvolvimento de projetos em P\&D. Fujino e Stal (2005) consideram, por exemplo, que a experiência da Fundação de Amparo à Pesquisa do Estado de São Paulo (FAPESP) com o programa PITE (Parceria para Inovação Tecnológica), lançado em 1995, trouxe bons resultados, mas poucos programas estaduais semelhantes foram implantados. Já o programa PIPE (Programa de Inovação Tecnológica em Pequenas Empresas), lançado em 1997, foi replicado em quase todos os estados. O PAPPE (Programa de Apoio à Pesquisa em Empresas) é implementado em parceria entre a Financiadora de Estudos e Projetos (FINEP) e as Fundações Estaduais de Apoio à Pesquisa, e tem como objetivo incentivar pesquisadores a abrirem empresas, transformando resultados de pesquisa em novos negócios. Existe a possibilidade de uma micro ou pequena empresa já existente querer lançar uma inovação, para a qual é possível contratar um pesquisador.

As duas pesquisadoras também relembram que a Lei de incentivos Fiscais para P\&D (Lei 11.196/05, que substitui a Lei 8.661/93) permite que as empresas deduzam do

\begin{tabular}{|l|l|l|l|l|l|}
\hline Interface da Educ. & Paranaíba & v. 1 & n. 1 & p. 53-65 & 2010 \\
\hline
\end{tabular}


imposto de renda devido, dentro de determinado limite, os valores gastos com atividades de pesquisa e desenvolvimento, tanto internas quanto contratadas em universidades ou institutos de pesquisa. A redução dos incentivos, em 1997, diminuiu expressivamente o interesse das empresas por esse mecanismo, mas a Lei de Inovação estabelece medidas de incentivo à pesquisa científica e tecnológica no ambiente produtivo, com vistas à capacitação, ao alcance da autonomia tecnológica e ao desenvolvimento industrial do país. Para estimular a construção de ambientes especializados e cooperativos de inovação, propõe a criação de um novo marco regulatório, que visa a estimular a geração de patentes e a transferência de tecnologia das universidades públicas para o setor privado. Ela deverá ser um dos principais pontos de referência da Política Industrial, Tecnológica e de Comércio Exterior (PITCE), anunciada em março de 2004.

Sem dúvida, o cenário brasileiro reflete um clima urgente à pesquisa acadêmica e à inovação, a própria sociedade já vem cobrando isso e o novo conceito de universidade do futuro propõe uma academia diretamente ligada ao desenvolvimento econômico e social do país. Para Fujino e Stal (2005), o problema é que, no Brasil, além de pouco investimento em pesquisa (total de $1,07 \%$ do PIB, dos quais apenas $0,4 \%$ vem da iniciativa privada), inexiste uma cultura para a inovação, o que decorre da carência de políticas de incentivos à atividade de pesquisa e ao desenvolvimento tecnológico.

Por isso, a Lei de Inovação pode ser valiosa por estimular e fixar regras mais claras para uma maior cooperação entre universidades e empresas, com maior impacto positivo sobre as universidades, pois a lei abre um espaço e dá maior segurança para o mercado também investir em pesquisas acadêmicas.

Se de um lado há a produção de pesquisa aliada ao desenvolvimento econômico e social do país, do outro, temos os profissionais ligados à academia, considerados como o mais importante e custoso recurso do ensino superior de qualquer nação. Segundo Elizabeth Balbachevsky, professora Doutora do Núcleo de Pesquisa do Ensino Superior da USP, os investimentos feitos no Brasil para dotar o país de uma massa crítica desses profissionais e garantir a qualidade de sua formação são antigos e tem permanecido elevados nos últimos quarenta anos. Os resultados desse empenho do governo e da sociedade brasileira podem hoje ser mensurados pelos impressionantes números de nossa pós-graduação, que formou, em 2002, quase 23.000 mestres e 7.000 doutores.

\begin{tabular}{|l|l|l|l|l|l|}
\hline Interface da Educ. & Paranaíba & v. 1 & n. 1 & p. 53-65 & 2010 \\
\hline
\end{tabular}


Como já assinalam vários estudiosos da educação, o ensino superior vem passando por transformações e uma tendência (conforme ALTBACH, 1969 e ENDERS, 2001 apud BALBACHEVSKY, 2001) é que essas mudanças costumam ser mencionadas em associação com algumas limitações da universidade, podendo ser detectadas em diferentes países desenvolvidos e em desenvolvimento. Uma das limitações apresentadas pelos autores é um aumento da crítica, por parte do governo e da sociedade, em relação aos resultados alcançados pelas instituições acadêmicas. Essas críticas questionam a qualidade e a inadequação do ensino oferecido por essas instituições, e a baixa relevância (econômica e social) do conhecimento produzido por seus profissionais.

Nos países desenvolvidos, as transformações já são visíveis e a Segunda Revolução Acadêmica está ocorrendo, considerando que as universidades destes países já ultrapassaram há muito tempo a fase de transformação de uma academia voltada para a transmissão de conhecimento para uma academia que agregou a pesquisa como atividade principal. Infelizmente, não é o caso da América Latina, onde há universidades que ainda prevalecem com o modelo antigo de ensino por transmissão do conhecimento, onde simplesmente não há pesquisa (BALBACHEVSKY, 2001). No Brasil, o cenário é um pouco melhor, se considerarmos o que foi dito anteriormente, que o país já passa por um processo embrionário da Segunda Revolução.

Outro ponto positivo é que as universidades do Brasil, como em muito outros países, gozam de uma ampla margem de autonomia para os acadêmicos. Pode-se dizer que "a profissão acadêmica determina o caráter da graduação. Os acadêmicos decidem o que o estudante deve conhecer, como deve aprender e quem o ensinará" (BALBACHEVSKY, 2001). As universidades possuem autonomia que lhes dão condições de planejar os seus próprios passos em direção ao desenvolvimento acadêmico.

Portanto, o perfil do professor do ensino superior, suas atitudes em relação à docência, pesquisa e atividade de extensão, sua responsabilidade na formação de futuros professores e pesquisadores constituem a pedra base da universidade. Todos sabem da importância do sucesso desse processo para o futuro do país. Os estudos internacionais também apontam com unanimidade a dimensão estratégica do ensino superior para o sucesso das faces socioeconômicas que proporcionam desenvolvimento sustentável em países do terceiro mundo.

\begin{tabular}{|l|l|l|l|l|l|}
\hline Interface da Educ. & Paranaíba & v. 1 & n. 1 & p. 53-65 & 2010 \\
\hline
\end{tabular}




\section{Considerações Finais}

O tema principal nas duas revoluções acadêmicas gira em torno da pesquisa. $\mathrm{Na}$ primeira revolução, a pesquisa vem para se tornar atividade principal da academia e, na segunda, já se faz necessário o movimento da pesquisa em direção à sociedade, na urgência de conectar universidade, governo e sociedade em busca de desenvolvimento socioeconômico para o país. Sem dúvida, o Brasil tem grandes desafios pela frente, a começar por passar completamente pela primeira revolução, haja vista que de um modo geral o nosso país não tem muita produção científica se comparado aos países desenvolvidos. Além disso, a Lei da Inovação (instrumento que amplia a relação entre universidade, governo e sociedade) ainda não se mostra tão conhecida nem mesmo nos ambientes acadêmicos, fato que pode ser comprovado com a ausência deste assunto durante os cursos de pós-graduação. Por outro lado, o Brasil é um país em desenvolvimento com recursos e potencial para fazer da pesquisa uma fonte geradora de crescimento sustentável para a sociedade. Contudo, o que buscou o presente artigo é resgatar o assunto e trazê-lo para as discussões dos profissionais acadêmicos, pois particularmente, acredito na força imensa que estes têm para transformar o país trazendo à luz as pesquisas produzidas e devolvendo-as sob forma de benefícios para a sociedade.

\section{Referências}

AUDY, Jorge Luis Nicolas. Universidade Inovadora: entre a tradição e a renovação. In: MOROSINI, Marília (Org.). A universidade no Brasil: concepções e modelos. Brasília: Instituto Nacional de Estudos e Pesquisas Educacionais Anísio Teixeira (INEP), 2006.

BALBACHEVSKY, Elizabeth. A profissão acadêmica no Brasil: evolução recente e perspectivas futuras. São Paulo: Núcleo de Pesquisas sobre Ensino Superior, NUPES, 2001. Disponível em: <http: www.usp.br/nupes/projeto.pdf>. Acesso em: 13 maio 2009.

DIEESE. Departamento Intersindical de Estatística e Estudos Socioeconômicos. Política Industrial no Brasil. Nota técnica, $\mathrm{n}^{\circ}$ 11, São Paulo, DIEESE, dez. de 2005.

FUJINO, Asa e STAL, Eva. As relações universidade-empresa no Brasil sob a ótica da Lei da Inovação. Revista de Administração e Inovação, v. 2, no 1, p. 05-19, São Paulo, 2005. Disponível em: <http://www.revista-rai.inf.br/ojs-2.1.1/index.php/rai/article/view/30/25>. Acesso em: 12 maio 2009.

\begin{tabular}{|l|l|l|l|l|l|}
\hline Interface da Educ. & Paranaíba & v. 1 & n. 1 & p. 53-65 & 2010 \\
\hline
\end{tabular}


NINIO, Marcelo. Número de patentes no Brasil decepciona ONU. Folha de São Paulo, São Paulo, 22 fev. 2008.

RISTOFF, Dilvo. A universidade brasileira contemporânea: tendências e perspectivas. In MOROSINI, Marília (Org.). A universidade no Brasil: concepções e modelos. Brasília: Instituto Nacional de Estudos e Pesquisas Educacionais Anísio Teixeira (INEP), 2006.

STAL, E. Centros de pesquisa cooperativa: um modelo eficaz de interação universidade empresa? 1997. 220 f. Tese (Doutorado) - Faculdade de Economia, Administração e Contabilidade, Universidade de São Paulo, São Paulo, 1997.

TOFFLER, A. Future Shock. New York: Bantam Books, 1970. 